\title{
Social support dimensions and components of performance in tennis
}

\author{
TIM REES, * DAVID K. INGLEDEW and LEW HARDY \\ School of Sport, Health and Physical Education Sciences, University of Wales, Bangor, Gwynedd LL57 2DG, UK
}

Accepted 24 October 1998

\begin{abstract}
The aim of this study was to explore the relationships between dimensions of social support and components of performance in tennis. A post-match performance measure was completed by 144 British tournament tennis players. Principal components analysis yielded eight components, labelled Execution of (Flexible) Plan, Loss of Composure, Feeling Flat, Positive Tension, Worry, Flow, Effective Tactics and Double Faults. Before the match, 46 players had also completed the Interpersonal Support Evaluation List. Stepwise regression analyses revealed significant effects of the Belonging and Appraisal dimensions of the Interpersonal Support Evaluation List on five of the performance components. The correlations between total support and four of these performance components were also significant. Logistic regression analyses revealed no significant effects of the dimensions of the Interpersonal Support Evaluation List or Total Support upon winning versus losing. Effects of social support upon performance were therefore only apparent when attention was focused on the components of performance.
\end{abstract}

Keywords: performance, social support, tennis.

\section{Introduction}

\section{Social support}

Anecdotal evidence suggests that individuals involved in elite-level sport frequently denigrate the use of social support. The prevailing attitude is that athletes often feel they must 'go it alone' (Hardy et al., 1996, p. 234) in their pursuit of success and not seek out social support in times of need. It has, nonetheless, been suggested that athletes should be encouraged to be proactive in their use of social support (Richman et al., 1989) and not consider such action a sign of weakness (Hardy and Crace, 1991).

Despite recommendations for research into social support in sport (e.g. Hardy and Jones, 1994), and despite the wealth of evidence pertaining to the positive effects of social support in the health literature (Cohen, 1988), comparatively little research has been undertaken on social support in sport. In sport, social support has, however, been linked empirically to cohesion. Westre and Weiss (1991) found that coaches, considered by their players to provide high social support, had players who perceived greater task cohesion in their

\footnotetext{
* Author to whom all correspondence should be addressed. e-mail: edp621@bangor.ac.uk
}

teams. The concept 'seeking social support' has been considered a coping strategy for dealing with competitive stress (Crocker, 1992) and slumps in performance (Madden et al., 1989). Social support has also figured prominently in burn-out. Gould et al. (1996) found that, as the competitive nature of tennis increased, players' support diminished, leading to a decreased ability to combat stress. Social support has also been suggested to play a role in both the aetiology of, and recovery from, injury (Hardy et al., 1991; Udry, 1996). In studies of leadership styles (for a review, see Chelladurai, 1993), players' perceptions of the socially supportive nature of their coach has been found to have an effect on players' satisfaction with the coach's leadership. Players' perceptions of, and preferences for, more socially supportive leadership from the coach have also been affected by players' age and ability. This research, and that from health psychology, suggests that the effects of being supported can be extremely beneficial. Conversely, the effects of not receiving support are potentially negative.

Given these findings, one could speculate whether social support also has a direct effect on sporting performance. I.G. Sarason et al. (1990) have argued convincingly that social support should have a direct effect on sports performance. For example, they suggest 
a performer may pull out of a slump simply because of the knowledge that a coach is available to provide technical support. At present, there is limited empirical evidence to support such a link. Weiss and Friedrichs (1986) did find that the social support dimension of the Leadership Scale for Sports (Chelladurai and Saleh, $1978,1980)$ was negatively associated with the win or loss percentage.

Cohen (1988) outlined four different models for the effects of social support on health, which may well apply to effects of social support on performance: information-based, identity and self-esteem, social influence and tangible-resource models. According to an information-based model, social support may provide advice regarding tactics and strategies and also information to help avoid stressors. According to an identity and self-esteem model, social support may give the player a sense of identity and belonging, increased self-esteem and perceived control. The positive psychological states suggested in this model may lead to increased positive affect and a greater motivation for good performance. A social influence model suggests that social controls and peer pressures may lead to a performer taking up performance-enhancing tactics and styles of play. A tangible-resource model suggests that social support may provide an overall feeling of stability by having tangible and economic aid at hand.

In speculating a link with performance, one is faced with a dilemma regarding measurement. Social support is a complex phenomenon, the meaning, nature and function of which are difficult to clarify (B.R. Sarason et al., 1990; Veiel and Baumann, 1992). This has led to a lack of consensus regarding its measurement. Nonetheless, it is considered that perceived support, as opposed to received support, may play a role in performance (I.G. Sarason et al., 1990).

Of the different perceived support measures, the Social Support Questionnaire (Sarason et al., 1983) measures support as a unitary construct. The Interpersonal Support Evaluation List (Cohen et al., 1985) can yield a total score, but also consists of four support dimension subscales. The Social Support Survey (Richman et al., 1993) is yet more differentiated, consisting of eight dimensions, developed from the sixdimensional conceptualization of support proposed by Pines et al. (1981). In the present study of tennis players, it seems reasonable to suggest that certain people may provide different types of social support to the individual in different circumstances. It was, therefore, considered appropriate to use a multidimensional measure of support for this study. However, in light of the arguments against differentiation of support dimensions (Sarason et al., 1987), it was also considered pertinent to measure overall support. The Interpersonal Support Evaluation List was deemed, therefore, the most appropriate measure for the present study, as it can account for total and multidimensional support. Brookings and Bolton (1988) noted that, in confirmatory factor analysis, the best fit for the Interpersonal Support Evaluation List was provided by the four-dimensional model, despite high intercorrelations among the dimensions. Their recommendation is to use the four-dimensional form of the model, but also, because of these high intercorrelations among dimensions, to use the total support score.

\section{Measuring performance}

In performance measurement, studies have tended to focus on outcome measures, such as winning versus losing. Criticism has been levelled at such research for using unstandardized performance measures (Gould et al., 1987). Similar to work on wrestlers (Gould et al., 1984), in tennis, where the standard of one's opponent differs with every match, this is particularly relevant. For example, one may play well one day but lose to a higherranked opponent. Conversely, one may play poorly but win an easy match. This has led to calls for more reliable and valid measurement of performance (Hardy and Jones, 1990; Gould and Krane, 1992). To this end, it has been suggested that performance assessment should include process measures (Gould et al., 1987) that may reflect the task complexity of different sports. Vealey (1992, 1994) has called for more process-oriented measurement in all areas of sport psychology. Jones (1995) reported that research examining more qualitative, process-oriented performance variables has been promising.

Tennis has provided some examples of alternative forms of performance assessment. Daw and Burton (1994) constructed tennis performance measurement instruments to reflect a player's self-reported general observation on how well he or she tends to play, and to assess perceptions of performance regarding mental skills only. The United Kingdom Lawn Tennis Association's (LTA) Tactical-Technical Evaluation Sheet assesses areas of tactics and technique. Mahoney et al. (1987) assessed the psychological skills underlying exceptional athletic performance. All these examples provide more information regarding the range of skills that might underlie tennis performance; but scope still exists for examining more closely the components of tennis performance. In the present study, a post-match measurement tool was derived from the perceptions of the players themselves.

\section{Present study}

In this study, we followed the guidelines for research suggested by Carron (1988) and Zanna and Fazio 
(1982). They suggested that initial research might look for a relationship between two variables before postulating greater theoretical links. The aim of this study was to observe the relationship between different social support dimensions and different components of tennis performance. The components of tennis performance were explored through the construction and principal components analysis of a performance assessment questionnaire. The effects of the social support dimensions upon the various components of performance were analysed using stepwise regression analyses, and the effects of total support using simple correlational analysis. To provide validation evidence for the use of a differentiated measure of performance, we considered it necessary to assess whether the components of performance differentiated winners and losers. Finally, the dimensions of social support and total support were examined with respect to their ability to predict winning versus losing.

Owing to the exploratory nature of this study, no hypotheses were made until after the results of the principal components analysis of the performance assessment questionnaire were known. At this point, we were able to hypothesize that the following performance components would be positively predicted by the social support dimensions: Execution of (Flexible) Plan, Positive Tension, Flow, and Effective Tactics. The following components would be negatively predicted: Loss of Composure, Feeling Flat, and Worry. No hypothesis was put forward for the prediction of the component Double Faults. More specific hypotheses were derived by considering how the social support dimensions of the Interpersonal Support Evaluation List (Appraisal, Belonging, Tangible and Self-esteem) might relate to the models of Cohen (1988), drawing upon Cutrona and Russell's (1990) comparisons of social support measures. We hypothesized that Appraisal would predict Execution of (Flexible) Plan and Effective Tactics; it might also predict Positive Tension and Worry. Belonging and Self-esteem would predict Feeling Flat and Flow; they might also predict Loss of Composure, Positive Tension and Worry. No specific hypotheses were put forward for the predictive effect of Tangible Support in this study, although Tangible Support might provide an overall sense of stability and security.

\section{Methods}

\section{Participants}

The participants were 144 British tournament tennis players (134 males, 10 females) aged $24 \pm 8$ years (mean $\pm s$ ). The players ranged from the British top-ten to lower-ranked but regular tournament players.
Recruitment of players was opportunistic (convenience sample) but widespread, with data collected from four geographically spread tournaments in the UK. The sample, however, contained fewer players from the top third $(3.5 \%)$ of the LTA ranking bands than the other two-thirds $(96.5 \%)$. This reflects reality (validated by the LTA) in that there are fewer players in these top ranks. All players were self-professed regular tournament players. Forty-six male competitors completed the Interpersonal Support Evaluation List before their matches; after the matches they completed the performance questionnaire. To increase the subject pool for the exploratory principal components analysis, an additional 98 players completed the performance questionnaire only.

\section{Measures}

Social support. Social support was measured using the Interpersonal Support Evaluation List (Cohen et al., 1985), which comprises Appraisal, Belonging, Tangible and Self-esteem dimensions (measured as subscales). Each item is marked true or false, and when coded can be summed to give a total score for each dimension subscale. Appraisal refers to support in the form of advice and discussion; Belonging refers to support in the form of identification with a social network; Tangible refers to support in the form of material aid; and Self-esteem refers to support in the form of favourable comparisons with others. Individual scale scores were computed. Also, a Total Support score was computed, by adding the four subscale scores. The Interpersonal Support Evaluation List (total support and subscales) had test-retest correlations of $0.63-0.70$ and internal consistency of $0.62-0.90$.

Performance. An original performance questionnaire was constructed for this study. At LTA tournaments during the summer of 1994, 28 players were asked to respond to the prompts, 'I know when I'm performing well, when I ...' and 'I know when I'm performing badly, when I . . . From this, a list of items relevant to tennis performance was generated. This list was then scrutinized by three LTA (professional grade) coaches and another 13 players. These individuals were asked to consider the validity of the items and to add to the list any further possibilities. From this, a 46-item questionnaire, with a rating scale from 0 (not at all) to 3 (a lot) was created, with the prompt 'During this match, to what extent did you ...', followed by the 46 items. This questionnaire was then piloted on a further group of seven players and one coach, generating a further seven items. The final questionnaire comprised 53 items relating to tennis performance. 


\section{Analyses}

Principal components analysis was used to examine the structure of the performance questionnaire. Listwise deletion for missing values was used. Components were retained if eigenvalues were greater than 1.0. The scree plot was also examined. Oblique rotation was used, with delta set at 0 for direct oblimin rotation. It was considered that while there may be different components comprising tennis performance, these components would quite likely be interrelated. The component scores were saved for use in the subsequent stepwise regression analyses.

Stepwise regression analysis and simple correlational analysis were used to examine the effects of the social support dimensions and Total Support upon the performance components. An alpha of 0.05 was used for all statistical tests, which were two-tailed. An inherent risk of the present study's use of multiple dependent variables in the stepwise regression analyses was an increased likelihood of committing Type I errors. Canonical correlation analysis would have been appropriate had there been more players in the study. However, only a subset of 46 of the 144 players in this study also completed the Interpersonal Support Evaluation List before their matches. Consequently, there were too few players to consider all variables simultaneously, as in a canonical correlation. Stepwise regression analysis was more appropriate in this case, because at any one time one was only looking at the association between one dependent variable and a small number of independent variables. The subject to variable ratio never fell below 10 to 1 . As this study was exploratory, it seemed acceptable to use stepwise regression analysis.

To validate this study's use of a differentiated performance measure, a multivariate analysis of variance was conducted to test whether those who won and those who lost differed on the components of performance, that is to say the saved component scores. Logistic regression analysis was then used to test whether the social support dimensions and Total Support might also predict winning versus losing.

\section{Results}

\section{Components of performance}

Histograms of the performance items revealed that, for every item, each of the response categories $(0,1,2,3)$ had been checked by at least one participant. A skewness statistic was computed for each item. Although none of the items was extremely skewed, six items had skewness greater than 1.0 in absolute terms. This meant that these items did not distinguish adequately between participants. Consequently, they were not included in subsequent analyses.
In the principal components analysis of the performance questionnaire, 10 components emerged with eigenvalues greater than 1.0, accounting for $72.1 \%$ of the variance. Examination of the pattern matrix revealed seven fairly distinct components and three ambiguous ones. Items were then eliminated if they had low loadings (less than 0.4 in absolute size) on all components, or ambiguous loadings (the difference between the highest loading and the next highest loading on any other component was less than 0.1). Using these criteria, 13 items were eliminated, leaving 34 items. These 34 items were subjected to a further principal components analysis. Eight components emerged with eigenvalues greater than 1.0, accounting for $69.7 \%$ of the variance (see Table 1).

These eight components were interpretable and labelled: (1) Execution of (Flexible) Plan; (2) Loss of Composure; (3) Feeling Flat; (4) Positive Tension; (5) Worry; (6) Flow; (7) Effective Tactics; and (8) Double Faults. At first, two of the components appeared to be ambiguous. These were Component 4 and Component 6. With respect to Component 4, the work of Idzikowski and Baddeley (1983) on public speaking was relevant. Their participants reported that they simultaneously felt alert, excited, energetic, troubled and tense; in other words, these feelings can co-exist. In the present study, the items for this component appeared to reflect this phenomenon. Consequently, we felt that Component 4 could be labelled Positive Tension. With respect to Component 6, the work of Csikszentmihalyi (1975) on the concept of flow was relevant, as the items reflected playing well and feeling good. Privette (1983) emphasized that flow incorporates elements of peak performance and peak experience. Consequently, we felt that Component 6 could be labelled Flow.

Component-component correlations (Table 1) showed that the components were fairly independent. Nevertheless, Execution of (Flexible) Plan correlated moderately with Flow $(r=0.40)$ and Effective Tactics $(r=0.36)$. Feeling Flat also correlated moderately but negatively with Flow $(r=-0.36)$.

\section{Effect of social support dimensions and Total Support on the components of performance}

The results from the stepwise regression analyses are shown in Table 2 . The explained variance $\left(R^{2}\right)$ is shown in the first column, the significance of which is shown in the next column. The sign of the regression coefficient in the final equation $(\beta)$ is taken to indicate the direction of the association between the independent and dependent variable.

Appraisal support predicted Execution of (Flexible) Plan $\left(R^{2}=0.17, P=0.01\right)$, Positive Tension $\left(R^{2}=0.12\right.$, 
Table 1 Final principal components analysis of performance items

Component

Item

1

$2 \quad 3$

4

5

0.77
0.72
0.63
0.61
0.52

0.77
0.72
0.63
0.61
0.52

$\begin{array}{ll}\text { Keep to a routine } & 0.77 \\ \text { Plan each point } & 0.72 \\ \text { Adapt to changing circumstances } & 0.63 \\ \text { Solve problems as they occur } & 0.61 \\ \text { Stay motivated } & 0.52\end{array}$

$\begin{array}{ll}\text { Keep to a routine } & 0.77 \\ \text { Plan each point } & 0.72 \\ \text { Adapt to changing circumstances } & 0.63 \\ \text { Solve problems as they occur } & 0.61 \\ \text { Stay motivated } & 0.52\end{array}$

Item-component loadings ${ }^{a}$

Keep to a routine

Think positively

0.49

0.37

0.47

0.37

$-0.31$

Keep a positive attitude

0.44

0.33

$-0.31$

Stay focused

Get wound up

Get angry

Fret about mistakes

Become aggressive

Let errors bother you

Lose your concentration

Feel sluggish

Feel mentally tired

Feel lively

Feel flat

Feel nervous

Work hard on each point

Become hesitant

Worry about your shots

Feel good

Keep a consistent standard

Keep your mind on the present

Enjoy yourself

Feel relaxed

See the ball well

Use effective strategies

Keep up the pressure on your opponent

Employ good tactics

Return serve well

Serve double faults

Move well
0.85
0.78
0.76
0.68
0.67
0.34

0.33

$$
\begin{array}{r}
0.94 \\
0.76 \\
-0.56 \\
0.47
\end{array}
$$

0.37

0.69

\begin{tabular}{|c|c|c|c|}
\hline \multirow{10}{*}{0.37} & & \multicolumn{2}{|l|}{0.78} \\
\hline & & \multicolumn{2}{|l|}{0.73} \\
\hline & & \multicolumn{2}{|l|}{0.64} \\
\hline & & \multicolumn{2}{|l|}{0.61} \\
\hline & -0.51 & \multicolumn{2}{|l|}{0.59} \\
\hline & & \multirow[t]{4}{*}{0.58} & 0.39 \\
\hline & & & 0.83 \\
\hline & & & 0.54 \\
\hline & & & 0.51 \\
\hline & & 0.44 & 0.50 \\
\hline
\end{tabular}

0.44

$$
0.88
$$

0.58

\section{Component-component correlations}

Component 1 (Execution of (Flexible) Plan)

Component 2 (Loss of Composure)

Component 3 (Feeling Flat)

Component 4 (Positive Tension)

Component 5 (Worry)

Component 6 (Flow)

Component 7 (Effective Tactics)

Component 8 (Double Faults)

-0.22
-0.23
0.09
-0.29
0.40
0.36
-0.08

$\begin{array}{rr}- & \\ 0.21 & - \\ -0.02 & -0.12 \\ 0.23 & 0.17 \\ -0.17 & -0.36 \\ -0.03 & -0.16 \\ 0.10 & -0.02\end{array}$$$
-0.01
$$$$
-0.01-
$$$$
0.14-0.28
$$$$
0.17-0.26
$$$$
\text { - }
$$$$
\begin{array}{lll}
0.00 & 0.12 & 0.02
\end{array}
$$$$
-0.09
$$

Note: $n=132 .{ }^{a}$ For clarity, only item-component loadings of 0.30 or more are shown.

$P=0.03)$ and Effective Tactics $\left(R^{2}=0.21, P<0.01\right)$, all in a positive direction. Belonging support predicted Feeling Flat $\left(R^{2}=0.12, P=0.03\right.$, association negative $)$ and Flow $\left(R^{2}=0.19, P<0.01\right.$, association positive).
Total Support was significantly correlated with Execution of (Flexible) Plan $(r=0.35, P=0.03)$, Feeling Flat $(r=-0.37, P=0.02)$, Flow $(r=0.44, P=0.01)$ and Effective Tactics $(r=0.43, P=0.01)$. 
Table 2 Stepwise regression analyses: Effects of social support dimensions on performance components

\begin{tabular}{|c|c|c|c|c|c|}
\hline $\begin{array}{l}\text { Dependent } \\
\text { variable }\end{array}$ & $\begin{array}{l}\text { Independent } \\
\text { variable }\end{array}$ & $\Delta R^{2 a}$ & $P(F)^{b}$ & $\beta^{c}$ & $P(t)^{d}$ \\
\hline $\begin{array}{l}\text { Execution of } \\
\text { (Elexible) Plan }\end{array}$ & Appraisal & 0.17 & 0.01 & 0.42 & 0.01 \\
\hline Feeling Flat & Belonging & 0.12 & 0.03 & -0.34 & 0.03 \\
\hline Positive Tension & Appraisal & 0.12 & 0.03 & 0.34 & 0.03 \\
\hline Flow & Belonging & 0.19 & 0.00 & 0.44 & 0.00 \\
\hline Eff ective Tactics & Appraisal & 0.21 & 0.00 & 0.46 & 0.00 \\
\hline
\end{tabular}

Note: $n=40 .{ }^{a}$ Predicted variance. ${ }^{b}$ Probability of $F$ for $R^{2} .{ }^{c}$ Standardized regression coefficient in final equation. ${ }^{d}$ Probability of $t$ for $\beta$.

Table 3 Multivariate analysis comparing winners and losers on performance components (mean $\pm s$ )

\begin{tabular}{lrrr}
\hline & & & $\begin{array}{c}\text { Standardized } \\
\text { structure } \\
\text { Dimension }\end{array}$ \\
& Winners & Losers & -0.43 \\
\hline Execution of (Flexible) Plan & $0.37 \pm 0.66$ & $-0.43 \pm 1.20$ & 0.02 \\
Loss of Composure & $0.01 \pm 0.87$ & $0.06 \pm 1.17$ & 0.33 \\
Feeling Flat & $-0.22 \pm 0.97$ & $0.40 \pm 0.94$ & -0.56 \\
Positive Tension & $0.38 \pm 0.72$ & $-0.69 \pm 1.19$ & 0.14 \\
Worry & $-0.14 \pm 0.87$ & $0.13 \pm 1.09$ & -0.22 \\
Flow & $0.05 \pm 1.01$ & $-0.39 \pm 1.03$ & -0.62 \\
Effective Tactics & $0.47 \pm 0.72$ & $-0.50 \pm 0.88$ & -0.07 \\
Double Faults & $-0.04 \pm 1.01$ & $0.10 \pm 0.97$ & \\
\hline
\end{tabular}

Note: $n=40$. Hotelling's $T^{2}=1.02, F_{8,31}=3.95, P<0.001 .{ }^{a}$ Component scores saved from final principal components analysis.

\section{Winning versus losing}

The multivariate analysis of variance indicated that those who won and those who lost their match did differ on the components of perceived performance (Hotelling's $T^{2}=1.02, F_{8,31}=3.95, P<0.001$ ). Followup discriminant function analysis suggested that the salient variables (standardized structure coefficients greater than 0.30 in absolute value, which Pedhazur, 1982, regarded as meaningful) were Execution of (Flexible) Plan (standardized structure coefficient -0.43), Feeling Flat (0.33), Positive Tension (-0.56) and Effective Tactics $(-0.62)$ (see Table 3$)$.

The logistic regression analyses revealed no significant effects of the social support dimensions or Total Support upon winning versus losing.

\section{Discussion}

In this study, we explored some of the components of performance in tennis through the construction and principal components analysis of a performance assessment questionnaire. The questionnaire was tennisspecific and asked individuals to refer to a specific match. Analysis yielded eight components, each of which could be interpreted without ambiguity: Execution of (Flexible) Plan, Loss of Composure, Feeling Flat, Positive Tension, Worry, Flow, Effective Tactics and Double Faults.

The study also examined the effects of the social support dimensions of the Interpersonal Support Evaluation List and Total Support upon the various components of performance. The social support measure was not context-specific. Nevertheless, significant differential effects were found for the social support dimensions and Total Support on the components of performance. The Appraisal dimension predicted Execution of (Flexible) Plan, Positive Tension and Effective Tactics; the prediction of Eff ective Tactics was the most highly significant. The Belonging dimension predicted Feeling Flat and Flow, the latter the most highly significant. Total Support predicted Execution of 
(Flexible) Plan, Effective Tactics, Feeling Flat and Flow, although, despite being less than alpha, none of these were highly significant. The multivariate analysis of variance indicated that winners and losers did differ on the components of perceived performance, the two most salient being Positive Tension and Effective Tactics. Logistic regression analyses found no significant effects of social support dimensions or Total Support on winning versus losing. It is clear that the effects of social support dimensions and Total Support upon performance were only apparent when the eight components of performance were used as the dependent variables.

Although it is important to note that no causal link can be inferred from this study, for the sake of clarity we do refer to effects of social support on performance components. Because the social support measure was a general one, it seems most unlikely that social support could have been caused by performance. The main problem was potential confounders. Indeed, this study, where all the measures were self-report, may well have been prone to negative affectivity bias (Watson and Pennebaker, 1989). The measure of social support might have been influenced by this nuisance factor. It could be that the performance components predicted by the social support dimensions and Total Support were also influenced by negative affectivity; in other words, the results were artefactual. It would appear that Feeling Flat, Flow and Positive Tension could readily be influenced by negative affectivity, but this does not appear to be so readily the case for Execution of (Flexible) Plan or Effective Tactics.

Although all of the items of the Interpersonal Support Evaluation List could be related to Sarason and colleagues' concept of unitary support (e.g. Sarason et al., 1987), Total Support only predicted four of the performance components. Consequently, despite acknowledging that 'knowing that one is loved and that others will do all they can when a problem arises may be the essence of social support' (I.G. Sarason et al., 1990, p. 119), the differential prediction of five performance components by the Appraisal and Belonging dimensions suggests that different components of performance are differentially affected by different aspects of support. Despite Sarason and co-workers' (1987) reservations regarding the functional multidimensionality of support, our results suggest the importance of measuring these functional aspects.

Cohen's (1988) models for the differential effects of social support on health are valid for our results of social support on performance. Following Cohen's models and the comparisons of support measures given by Cutrona and Russell (1990), Appraisal might therefore serve to provide advice which influences performance directly. This might be information about the opponent or information regarding certain tactics and game plans.
Appraisal might also help the player to stay positive in the face of stressful tension. In an identify and selfesteem model, Belonging may lead to less despondency and anxiety, and to increased positive affect, thereby preventing the player from feeling flat. Furthermore, the positive thought patterns associated with Belonging support may also increase the likelihood of the player experiencing elements of Flow. It is somewhat surprising that Self-esteem support did not predict performance components, given the evidence for the powerful effect of self-confidence on performance (Hemery, 1986; Jones and Hardy, 1990). Tangible support did not predict any performance components, although its influence could be extremely important, given the excessive financial cost of pursuing a career on the tennis circuit.

What are the practical implications of these findings? The multi-component solution for performance could have interesting implications for intervention. In particular, the more one is able to pinpoint areas of deficiency in performance, the better one may be able to implement intervention (Parfitt et al., 1990).

The beneficial effects of social support on performance suggest that good social support may be an important part of a competitor's make-up. However, a lack of social support cannot instantly command a remedy. Forcing social support onto tennis players who lack support is a complicated issue, in that it is ethically problematic. One may have to accept that players are quite capable of creating their own social support. It may perhaps be more important to help them not to undermine the social support that is already available to them, rather than giving support to them. Richman et al. $(1989$, p. 158) felt that quality social support needed 'to be purposefully developed and nurtured'. It has been suggested that athletes should be encouraged to seek out social support from a variety of different people and to maximize and build on the support currently available to them. Richman et al. (1989) further commented that social support should be considered within a proactive model, with the athlete recognizing support needs and acting to satisfy those needs. Clearly, the benefits of social support should not be underestimated. Despite some of the misgivings regarding the use of social support, there are sporting advocates, such as the professional ten-pin bowler in Gould and Finch's (1990) study, who maintain that the most important lesson they have learned is to use social support.

Clearly, Cohen's (1988) models provide an interesting insight into the ways in which social support may affect performance. However, our comments here are merely speculations in need of further empirical support. Although social support did predict quite well, it could be argued that a more sport-specific questionnaire would serve as a better indicator of the types of 
support used by tennis players. For example, it may be worth including indications of the kind of support offered by coaches or other players. A counterargument would be to note that a less specific measure of social support provides a more generalizable result (Gauvin and Russell, 1993). Rosenfeld et al. (1989) examined the differential provision of support from coaches, teammates, friends and parents. However, validation of the Social Support Survey (Richman et al., 1993) does not reveal whether all eight dimensions of support can be clearly separated.

According to Carron (1988) and Zanna and Fazio (1982), a second-generation question would be to examine possible moderator variables, so that findings such as those reported here may be placed in a more theoretical context. Given the literature on the 'stressbuffering' effect of social support on health (Cohen, 1988), and the literature on stress and performance (Jones and Hardy, 1990), a first step might be to examine whether social support moderates the effect of stress upon performance. Comments, such as those noted in Gould et al. (1993), do allude to this potential. They suggest that elite performers should 'seek and utilise social support. Use family, friends and coaches for support rather than trying to deal with the pressure all by yourself' (Gould et al., 1993, p. 369). It is important to note, however, that stress-buffering may only occur if the needs dictated by the stressful event are matched by the functions of the support that is perceived to be available (Cohen and McKay, 1984; Cohen and Wills, 1985; Cutrona and Russell, 1990). As noted earlier, this implies that a closer examination of the kind of support specific to sporting contexts is required, as opposed to the use of generic support measures. It also implies careful examination of the many stressors that may befall a sportsperson.

Although the performance questionnaire was constructed specifically for tennis, and some of the items are tennis-specific, most of the components appear generally applicable to any sport. Naturally, the component Double Faults is tennis-specific, but the other components (e.g. Flow, Effective Tactics and Loss of Composure) could be relevant in other sporting contexts. It would be of interest to see the extent to which the component structure obtained in the present study is replicable in other sporting contexts. The performance questionnaire provides further insight into performance assessment. It deals not with outcomes of performance, but with the different components of performance. Nevertheless, despite the intuitive appeal of these results, it would be sensible to perform a confirmatory factor analysis of the performance questionnaire in subsequent studies.

The significant effects of the social support dimensions and Total Support on some of the performance components suggest a positive role for social support in sport. The results found no such significant effects of the predictor variables on the win or loss outcome measure. This exploratory research, therefore, has identified effects of the social support dimensions and Total Support upon performance that are only apparent when attention is paid to the components of performance, in this case as perceived by the performers.

\section{References}

Brookings, J.B. and Bolton, B. (1988). Confirmatory factor analysis of the Interpersonal Support Evaluation List. American fournal of Community Psychology, 16, 137-147.

Carron, A.V. (1988). Group Dynamics in Sport. London, ON: Spodym.

Chelladurai, P. (1993). Leadership. In Handbook of Research on Sport Psychology (edited by R.N. Singer, M. Murphey and L.K. Tennant), pp. 647-671. New York: Macmillan.

Chelladurai, P. and Saleh, S.D. (1978). Preferred leadership in sports. Canadian fournal of Applied Sport Sciences, 3, 85-92.

Chelladurai, P. and Saleh, S.D. (1980). Dimensions of leader behaviour in sports: Development of a leadership scale. Fournal of Sport Psychology, 2, 34-45.

Cohen, S. (1988). Psychosocial models of the role of social support in the etiology of physical disease. Health Psychology, 7, 269-297.

Cohen, S. and McKay, G. (1984). Social support, stress and the buffering hypothesis: A theoretical analysis. In Handbook of Psychology and Health (edited by A. Baum, S.E. Taylor and J.E. Singer), pp. 253-267. Hillsdale, NJ: Erlbaum.

Cohen, S. and Wills, T.A. (1985). Stress, social support and the buffering hypothesis. Psychological Bulletin, 98, 310357.

Cohen, S., Mermelstein, R., Kamarck, T. and Hoberman, H. (1985). Measuring the functional components of social support. In Social Support: Theory, Research, and Applications (edited by I.G. Sarason and B.R. Sarason), pp. 73-94. Dordrecht: Martinus Nijhoff.

Crocker, P.R.E. (1992). Managing stress by competitive athletes: Ways of coping. International fournal of Sport Psychology, 23, 161-175.

Csikszentmihalyi, M. (1975). Beyond Boredom and Anxiety. San Francisco, CA: Jossey-Bass.

Cutrona, C.E. and Russell, D.W. (1990). Type of social support and specific stress: Toward a theory of optimal matching. In Social Support: An Interactional View (edited by B.R. Sarason, I.G. Sarason and G.R. Pierce), pp. 319-366. New York: Wiley.

Daw, J. and Burton, D. (1994). Evaluation of a comprehensive psychological skills training program for collegiate tennis players. The Sport Psychologist, 8, 37-57.

Gauvin, L. and Russell, S.J. (1993). Sport-specific and culturally adapted measures in sport and exercise psychology research: Issues and strategies. In Handbook of Research on Sport Psychology (edited by R.N. Singer, M. Murphey and L.K. Tennant), pp. 891-900. New York: Macmillan. 
Gould, D. and Finch, L. (1990). Sport psychology and the professional bowler: The case of Michelle Mullen. The Sport Psychologist, 4, 418-430.

Gould, D. and Krane, V. (1992). The arousal-athletic performance relationship: Current status and future directions. In Advances in Sport Psychology (edited by T.S. Horn), pp. 119-141. Champaign, IL: Human Kinetics.

Gould, D., Petlichkoff, L. and Weinberg, R.S. (1984). Antecedents of, temporal changes in, and relationships between CSAI-2 subcomponents. Fournal of Sport Psychology, 6, 289-304.

Gould, D., Petlichkoff, L., Simons, J. and Vevera, M. (1987). Relationship between Competitive State Anxiety Inventory-2 subscale scores and pistol shooting performance. Fournal of Sport Psychology, 9, 33-42.

Gould, D., Jackson, S.A. and Finch, L.M. (1993). Life at the top: The experiences of U.S. National Champion figure skaters. The Sport Psychologist, 7, 354-374.

Gould, D., Tuffey, S., Udry, E. and Loehr, J. (1996). Burnout in competitive junior tennis players. II: Qualitative analysis. The Sport Psychologist, 10, 341-366.

Hardy, C.J. and Crace, R.K. (1991). Social support within sport. Sport Psychology Training Bulletin, 3, 1-8.

Hardy, C.J., Richman, J.M. and Rosenfeld, L.B. (1991). The role of social support in the life stress/injury relationship. The Sport Psychologist, 5, 128-139.

Hardy, L. and Jones, G. (1990). Future directions for research into stress in sport. In Stress and Performance in Sport (edited by G. Jones and L. Hardy), pp. 281-296. Chichester: Wiley.

Hardy, L. and Jones, G. (1994). Current issues and future directions for performance-related research in sport psychology. Fournal of Sports Sciences, 12, 61-92.

Hardy, L., Jones, G. and Gould, D. (1996). Understanding Psychological Preparation for Sport: Theory and Practice of Elite Performers. Chichester: Wiley.

Hemery, D. (1986). The Pursuit of Sporting Excellence. London: Collins.

Idzikowski, C. and Baddeley, A. (1983). Waiting in the wings: Apprehension, public speaking and performance. Ergonomics, 26, 575-583.

Jones, G. (1995). More than just a game: Research, developments and issues in competitive anxiety in sport. British fournal of Psychology, 86, 449-479.

Jones, G. and Hardy, L. (eds) (1990). Stress and Performance in Sport. Chichester: Wiley.

Madden, C.C., Kirkby, R.J. and McDonald, D. (1989). Coping styles of competitive middle distance runners. International fournal of Sport Psychology, 20, 287-296.

Mahoney, M.J., Gabriel, T.J. and Perkins, T.S. (1987). Psychological skills and exceptional athletic performance. The Sport Psychologist, 1, 181-199.

Parfitt, G., Jones, G. and Hardy, L. (1990). Multidimensional anxiety and performance. In Stress and Performance in Sport (edited by G. Jones and L. Hardy), pp. 43-80. Chichester: Wiley.

Pedhazur, E.J. (1982). Multiple Regression in Behavioral Research. New York: Holt, Rinehart \& Winston.
Pines, A.M., Aronson, E. and Kafry, D. (1981).Burnout: From Tedium to Personal Growth. New York: Free Press.

Privette, G. (1983). Peak experience, peak performance, and flow: A comparative analysis of positive human experiences. Fournal of Personality and Social Psychology, 45, 13611368.

Richman, J.M., Hardy, C.J., Rosenfeld, L.B. and Callanan, R.A.E. (1989). Strategies for enhancing social support networks in sport: A brainstorming experience. Fournal of Applied Sport Psychology, 1, 150-159.

Richman, J.M., Rosenfeld, L.B. and Hardy, C.J. (1993). The Social Support Survey: A validation of a clinical measure of the social support process. Research on Social Work Practice, 3, 288-311.

Rosenfeld, L.B., Richman, J.M. and Hardy, C.J. (1989). An examination of social support networks among athletes: Description and relationship to stress. The Sport Psychologist, 3, 23-33.

Sarason, B.R., Shearin, E.N., Pierce, G.R. and Sarason, I.G. (1987). Interrelations of social support measures: Theoretical and practical implications. Fournal of Personality and Social Psychology, 52, 813-832.

Sarason, B.R., Sarason, I.G. and Pierce, G.R. (1990). Social Support: An Interactional View. New York: Wiley.

Sarason, I.G., Levine, H.M., Basham, R.B. and Sarason, B.R. (1983). Assessing social support: The Social Support Questionnaire. Fournal of Personality and Social Psychology, 44, 127-139.

Sarason, I.G., Sarason, B.R. and Pierce, G.R. (1990). Social support, personality and performance. Fournal of Applied Sport Psychology, 2, 117-127.

Udry, E. (1996). Social support: Exploring its role in the context of athletic injuries. Fournal of Sport Rehabilitation, 5, 151-163.

Vealey, R. (1992). Personality and sport: A comprehensive view. In Advances in Sport Psychology (edited by T.S. Horn), pp. 25-59. Champaign, IL: Human Kinetics.

Vealey, R. (1994). Knowledge development and implementation in sport psychology: A review of The Sport Psychologist, 1987-1992. The Sport Psychologist, 8, 331348.

Veiel, H.O.F. and Baumann, U. (1992). The Meaning and Measurement of Social Support. New York: Hemisphere.

Watson, D. and Pennebaker, J.W. (1989). Health complaints, stress, and distress: Exploring the central role of negative affectivity. Psychological Review, 96, 234-254.

Weiss, M.R. and Friedrichs, W.D. (1986). The influence of leader behaviours, coach attributes, and institutional variables on performance and satisfaction of collegiate basketball teams. Fournal of Sport Psychology, 8, 332-346.

Westre, K. and Weiss, M. (1991). The relationship between perceived coaching behaviours and group cohesion in high school football teams. The Sport Psychologist, 5, 41-54.

Zanna, M.P. and Fazio, R.H. (1982). The attitude-behavior relation: Moving toward a third generation of research. In Consistency in Social Behavior: The Ontario Symposium (edited by M.P. Zanna, E.T. Higgins and C.P. Herman), Vol. 2, pp. 283-301. Hillsdale, NJ: Erlbaum. 